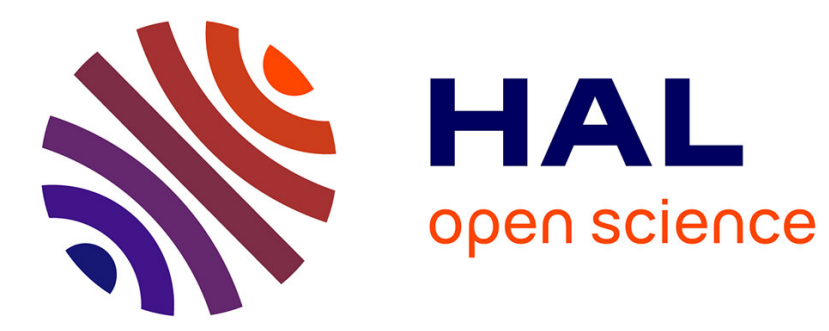

\title{
Molecular Tweezers: Concepts and Applications
}

\author{
Jeanne Leblond, Anne Petitjean
}

\section{- To cite this version:}

Jeanne Leblond, Anne Petitjean. Molecular Tweezers: Concepts and Applications. ChemPhysChem, 2011, 10.1002/cphc.201001050 . hal-02512503

\section{HAL Id: hal-02512503 \\ https://hal.science/hal-02512503}

Submitted on 1 Apr 2020

HAL is a multi-disciplinary open access archive for the deposit and dissemination of scientific research documents, whether they are published or not. The documents may come from teaching and research institutions in France or abroad, or from public or private research centers.
L'archive ouverte pluridisciplinaire HAL, est destinée au dépôt et à la diffusion de documents scientifiques de niveau recherche, publiés ou non, émanant des établissements d'enseignement et de recherche français ou étrangers, des laboratoires publics ou privés. 


\title{
Molecular Tweezers: Concepts and Applications.
}

\author{
Jeanne Leblond, ${ }^{[\mathrm{b}]}$ and Anne Petitjean*[a]
}

\author{
In Memory of Dr Bernard Dietrich
}

Taken to the molecular level, the concept of 'tweezers' opens a rich and fascinating field at the convergence of molecular recognition, biomimetic chemistry and nano-machines. Composed of a spacer bridging two interaction sites, the behaviour of molecular tweezers are strongly influenced by the flexibility of their spacer. Operating through an 'induced-fit' recognition mechanism, flexible molecular tweezers select the conformation(s) most appropriate for substrate binding. Their adaptability allows them to be used in a variety of binding modes and have found applications in chirality signaling. Rigid spacers, on the contrary, display a limited number of binding states, leading to selective and strong substrate binding following a 'lock and key' model. Exquisite selectivity may be expressed with substrates as varied as $C_{60}$, nanotubes and natural cofactors, and applications to molecular electronics and enzyme inhibition are emerging. At the cross-road between flexible and rigid spacers, stimulus responsive molecular tweezers controlled by ionic, redox or light triggers belong to the realm of molecular machines, and, applied to molecular tweezing, open doors to the selective binding, transport and release of their cargo. Applications to controlled drug delivery are already appearing. The past thirty years have seen the birth of molecular tweezers; the next many years to come will surely see them blooming in exciting applications.

\section{Introduction}

Molecular tweezers are synthetic molecular receptors with an open cavity defined by two interaction sites (IS, Scheme 1) for substrate binding, bridged by a spacer (S, Scheme 1$)$.

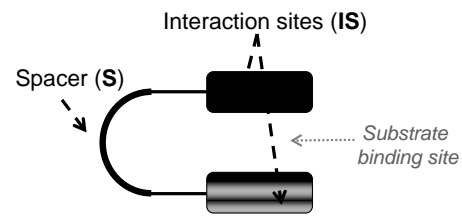

Scheme 1: Cartoon representation of interacting site (IS) and spacer (S) components of molecular tweezers, and their relationship with substrate binding.

In the last thirty years, they have received increasing attention due to their relevance at several levels. On a macroscopic level, the mechanical action of everyday life tweezers is easily understood. On a nanoscopic level, molecular tweezers gather the minimal information to mimic biological recognition and selectivity: the combination of specific electronic information contained in IS and the control of their spatial separation by $\mathbf{S}$ provides the source of selective recognition. Furthermore, the potential to control the relative orientation of the IS sites through stimulus responsive spacers (S) mimics the allosteric control frequently found in natural systems such as enzymes. ${ }^{[1 a-d]}$

This review highlights the basic features of reported molecular tweezers,${ }^{[1 \mathrm{e}-\varepsilon]}$ based on the nature and flexibility of the spacer $\mathbf{S}$ group. Indeed, the nature of the spacer plays a critical role in the recognition process, as recently illustrated by Zhu et al. with tweezers including the same IS linked by various $\mathbf{S}$, and yet capable of distinguishing specific imide sites along a polymer chain based on the nature of the spacer $\mathbf{S}^{\left[{ }^{[2]}\right.}$ Three types of spacers will be discussed in this mini-review: flexible, rigid and switchable (Scheme 2), although borderline examples share features from each category.

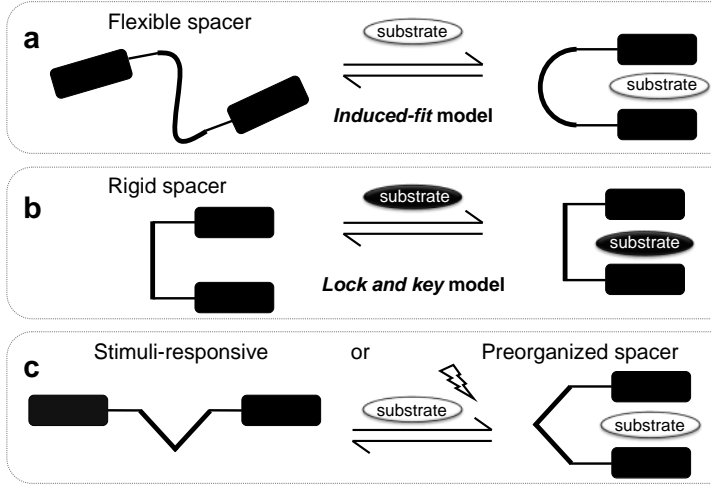

Scheme 2: Cartoon representation of (a) flexible tweezers ('induced-fit' mechanism), (b) rigid tweezers ('lock and key' model), and (c) stimuli responsive and pre-organized spacers.

[a] Dr Anne Petitjean

Department of Chemistry, Queen's University, Chernoff Hall 90 Bader Lane

Kingston, ON, K7L3N6, Canada

Fax: (+1) 6135336669

E-mail:anne.petitjean@chem.queensu.ca

[b] Dr Jeanne Leblond

Faculté de Pharmacie, Université de Montréal,

PO Box 6128 Doxntown Station

Montréal QC H3C 3J7, Canada

Fax: (+1) 5143436871

E-mail: jeanne.chain@umontreal.ca 
Examples of weak interactions ${ }^{[3]}$ present at IS sites are introduced and applications discussed within this framework. Ranked from most energetic to less energetic, they involve coordination bonds, ion-ion interactions, $\mathrm{H}$-bonding, ion-dipole, ion- $\pi, \pi-\pi$ and van der Waals interactions, tuned by the nature of the solvent. Hydrophobic effects are also important in water soluble molecular tweezers targeting natural substrates, as seen below.

Although many potential molecular receptors have been described as molecular tweezers because of their shape, this review mostly focuses on those for which substrate binding through intermolecular forces has been explored.

\section{Flexible spacers}

\subsection{Flexible linkers: molecular tweezers adjusting to the substrate}

In their pioneering work, Chen and Whitlock proposed flexible water soluble tweezers where two caffeine units (IS) were linked by a flexible spacer (S) composed of alkyl-diyne units. ${ }^{[4 a]}$ Among the various molecular conformations accessible through rotation around $\mathrm{C}-\mathrm{C}$ bonds, the one that brought the IS sites into a parallel orientation (ideal for substrate binding) was selected by hydrophobic benzoate and naphthoate anionic guests. ${ }^{[4 a]}$ The binding of such aromatic guests illustrates the 'induced-fit' model originally stated for biological systems. ${ }^{[4 b]}$ In this model, the substrate selects the receptor's conformation(s) which is (are) most appropriate for binding (Scheme 2a). This 'induced fit' model implies: (i) that the spacer $\mathbf{S}$ offers enough flexibility to fit the substrate and (ii) that a strong interaction between the IS and the substrate exists in order to compensate for the significant entropic loss associated with substrate binding. As a result, only the strongest intermolecular forces are found in flexible tweezers where the spacer is a simple, linear chain: hydrophobic effects with aromatic guests in water soluble tweezers, ${ }^{[4 a]}$ coordination bonds mostly based on the axial ligation of porphyrin metal complexes, ${ }^{[5 a-e]}$ or the synergistic effect of combined weak interactions (e.g. ion-dipole + donor/acceptor, ${ }^{[5]}$ ion-ion $+\mathrm{H}$ bonding ${ }^{[59]}$.

In all cases, the flexibility of the tweezers offers severa advantages: first, versatility in the substrate to be complexed, due to the multiple conformations the tweezer can adopt, while the length of the spacer confers some degree of selectivity. ${ }^{[5 a-e, g]}$ Second, the conformational selection operated by substrate binding may induce a detectable signal to be used for sensing. For instance, the absolute configuration of chiral diamines, ${ }^{[5 a, e]}$ amines, ${ }^{[5 b]}$ alcohols, ${ }^{[5 b]}$ diols, ${ }^{[5 e]}$ aminoalcohols, ${ }^{[5 a, b, e]} \alpha$-chiral carboxylic acids ${ }^{[5 c]}$ and $\alpha$-hydroxyketones ${ }^{[5 d]}$ may be determined through the circular dichroism signal (CD) induced by bidendate chiral substrates into the metalloporphyrin-based tweezer receptor 1 (Figure 1). ${ }^{[5-e]}$ In such cases, the conformational selection combined with the substrate-induced rigidification of the complex lead to efficient chirality transfer from the chiral guest to the achiral host, and thereby to high optical activity. ${ }^{[5 a]}$ However, significant spacer flexibility may also limit selectivity and allow various stoechiometries of substrate binding. ${ }^{[59]}$
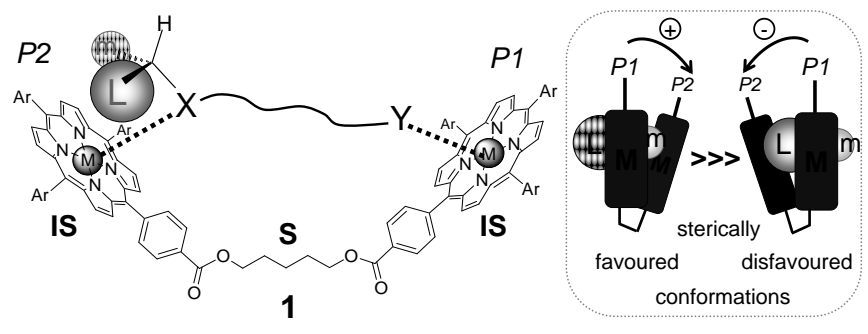

Figure 1: Flexible tweezers based on porphyrin complexes $\left(\mathrm{M}=\mathrm{Zn}^{2+}\right.$ or $\left.\mathrm{Mg}^{2+}\right)$ accommodate chiral bidentate substrates $(X, Y=N$ or $O)$ and signal their absolute configuration by induced circular dichroism. ${ }^{\text {[5a-e] }}$ Insert: schematic explanation for the substrate-induced positive exciton based on sterics.

\subsection{Semi-flexible linkers}

Complete rotational freedom of movement within the spacer however limits binding affinity because of the entropic cost associated with conformational state selection upon substrate binding. Such entropic cost may be partially paid for during the synthesis of the receptor by only allowing few predetermined receptor conformations prior to binding. Such conformational restrictions may be provided by spacers $\mathbf{S}$ made of rigid (aromatic, ${ }^{[6 a-h, n, 7 a-c]}$ conjugated $^{[6]]}$ or aliphatic ${ }^{[6, k]}$ ) scaffolds connected to IS by simple aliphatic hinges (Figure $2 \mathrm{a})^{[6]}$ or by single bond with free rotation (Figure $2 \mathrm{~b}$ ). ${ }^{[7]}$ Aliphatic hinges may also be duplicated in order to rigidify the overall structure (grey lines as in tetrasubstituted benzenes ${ }^{[6,, n]}$ and glycouril units, ${ }^{[6, k]}$ Figure 2a).

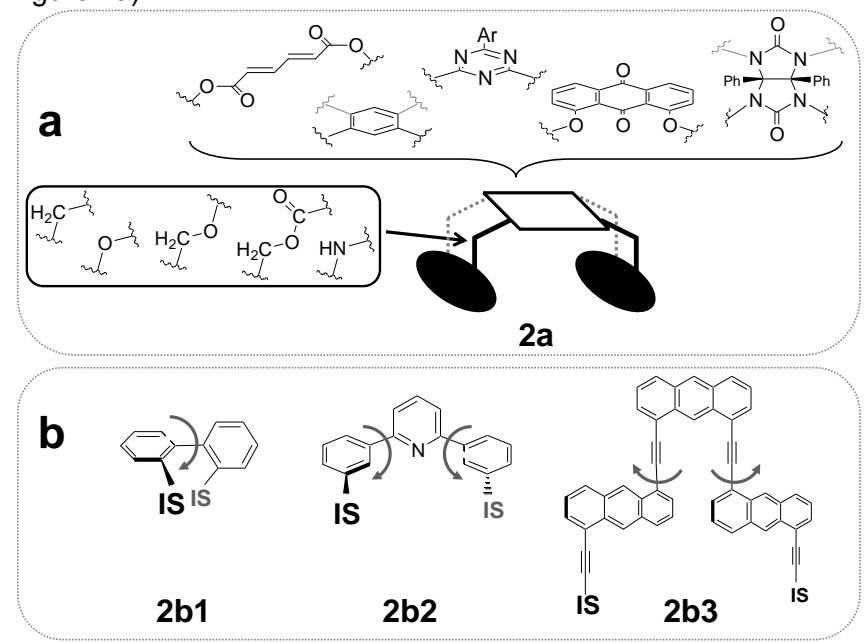

Figure 2: General design of semi-flexible molecular tweezers based on (a) single or double aliphatic hinges and (b) free bond rotation. Common interaction sites (IS) involve coordination to metalloporphyrins, ${ }^{[6 \mathrm{e}-\mathrm{g}, 7 \mathrm{cc}]}$ hydrogen-bonding, ${ }^{[7 \mathrm{a}]}$ ion-ion interactions, ${ }^{[7 a]} \pi-\pi$ interactions ${ }^{[6 a, c, d, i-k, n, 7 b, c]}$ and van der Waals interactions with steroids. $\left.{ }^{[6]}\right]$

Although a few degrees of freedom remain in the receptor, binding constants with semi-flexible tweezers are sometimes nearly comparable to fully rigid analogues. ${ }^{[7 b]}$ However, the relative flexibility allows for the opening of the cavity, its adjustment to various substrates ${ }^{[7 \mathrm{c}]}$ (occasionally accompanied with a mechanical "chewing" motion ${ }^{[6 h]}$ ) and access to higher association orders (e.g., not only $1: 1$ but $1: 2^{[7 a]}$ and $2: 2^{[6 \mathrm{~d}]}$ stoichiometries, Figure 3). 


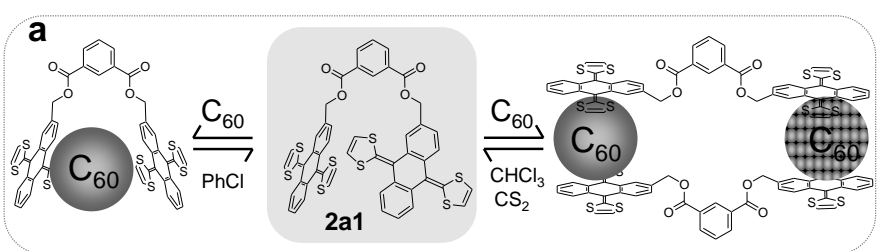

b
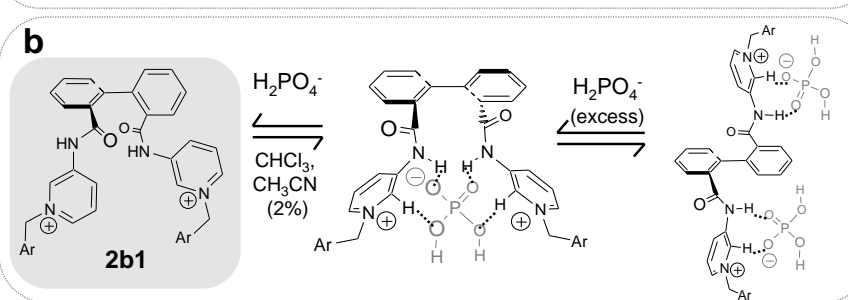

Figure 3: Semi-flexible molecular tweezers based on (a) an aliphatic hinge ${ }^{[6 \mathrm{~d}]}$ and (b) C-C bond rotation. ${ }^{[7 a]}$ In both cases, higher association orders may be observed (in 2a1, a 2+2 stoichiometry has been suggested depending on the nature of the solvent $\left.{ }^{[7 a]}\right)$.

Due to their synthetic accessibility, their significant binding strength and fair and adjustable selectivity resulting from tunable cavities, semi-flexible spacers and the resulting molecular tweezers have found applications as varied as receptors for anions ${ }^{[6, \mathrm{~m}, 7 \mathrm{a}]}$ and for cholesterol based on imprinted polymers, ${ }^{[6 \mathrm{~b}]}$ and as chiral enantio-differentiating NMR agents. ${ }^{[6]}$

\section{Rigid spacers}

\subsection{Rigid spacers maintained by fused rings}

Gaining in rigidity to the detriment of flexibility reflects a transition from the host-guest 'induced fit' model to the 'lock and key' model, stated by Fischer ${ }^{[8 a]}$ In this model, the substrate fits in the receptor like a key in a lock (Scheme $2 b$ ). The rigid preorganization of the host minimizes the entropic cost of conformational selection, and, therefore, significantly increases binding strength. For instance, a spacer with a controlled geometry presenting two parallel interaction sites separated by $\sim 7$ $\AA$ facilitates complexation of aromatic substrates, ${ }^{\left[{ }^{[b]}\right.}$ as in Zimmerman's fused aromatic (or mixed unsaturated-saturated) spacers $^{[9]}$ enforcing a syn-conformation between both IS units (Figure 4). Combined with anthracene IS, such rigid spacer induces high affinities for electron acceptors (e.g., 3a(9-anthryl) complexes 2,4,5,7-tetranitrofluorenone (TENF) with a binding constant of $2.10^{4} \mathrm{M}^{-1}$ in $\mathrm{CDCl}_{3}{ }^{[9 \mathrm{c}]}$ ) and good selectivity for nucleosides when $\mathrm{H}$-bonding is added in the cleft (3c spacer, Figure 4). ${ }^{\left[{ }^{d]}\right]}$ Using spacer 3a, Zimmerman et al. assessed the effect of the rigid saturated ethano bridges (circled in Figure 4 left) on the binding constants of acridyl IS to TENF, or, in other words, the benefit of freezing $\mathrm{C}-\mathrm{C}$ bond rotation. ${ }^{\left[{ }^{9 c]}\right.}$ They found that transitioning from a semi-flexible (no ethano bridge) to a semi-rigid (one ethano bridge) to a fully rigid receptor (two ethano bridges) increased the free energy of binding by $\sim 3.8 \mathrm{kJmol}^{-1}$ per frozen $\mathrm{C}-\mathrm{C}$ bond (the binding constant is multiplied $\sim 4-5$ fold for each frozen $\mathrm{C}-\mathrm{C}$ bond). ${ }^{[9 \mathrm{c}]}$ Using spacer $\mathbf{3 a}$, rigid molecular tweezers offering IS composed of planar coordination complexes, ${ }^{[10]}$ such as terpyridyl-Pd" (Figure 4 right), accommodate aromatic guests as well as planar metal complexes. ${ }^{[10 a-c]}$ In this case, metal-metal interactions add to aromatic stacking to tighten the complex, as evidenced by the reduction of the $\pi-\pi$ distance $(3.2 \AA$ vs $3.5 \AA) .{ }^{[10 a]}$ Although kinetically labile (i.e., the substrates may exchange or reorient in a rapid equilibrium), these complexes are highly thermodynamically stable. ${ }^{[10 \mathrm{~b}]}$ Metal-based IS also allow multidentate ligands to be used in the assembly of more complex supramolecular receptors such as 2D rectangles and 3D-prisms with multiple binding sites. ${ }^{[10 c]}$ Finally, varying the nature of the fused aromatic rings (e.g., anthracene, xanthene) allows to tune the size of the cavity and relative orientations of the interaction sites. ${ }^{[10 f]}$

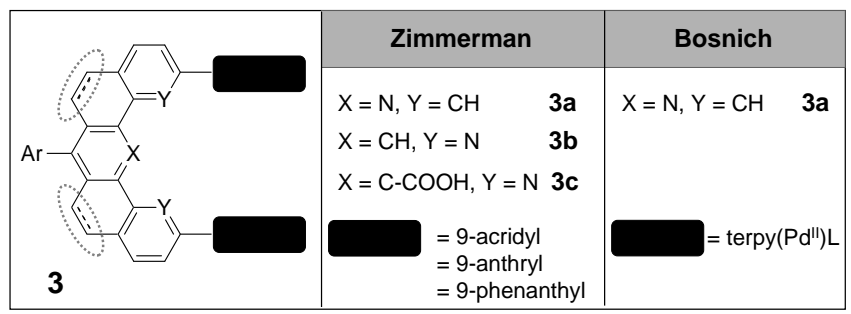

Figure 4: Rigid tweezers developed by Zimmerman and Bosnich around common locked structures for spacer $\mathbf{S} .^{[9,10]}$ The circled ethano/etheno bridges confer rigidity to the molecular tweezers.

Fully saturated rings have also been used to prepare molecular tweezers taking full advantage of the conformational preference of individual disubstituted cyclohexyl rings ${ }^{[11 a, b]}$ (Figure $5 a$ ) or fused systems (Figure $5 b$ ) of natural (e.g., bile acid derivatives) $)^{[11 c, d]}$ or synthetic ${ }^{[11 \mathrm{e}, \mathrm{f}]}$ origin (Figure $5 b$ ), generating a variety of cavity sizes.

Molecular tweezers do not necessarily offer parallel interaction sites. Substrates with curvature may be best accommodated by receptors with interaction sites maintained in a curved, diverging orientation enforced by appropriate rigid spacers. For instance, selective binding of $\mathrm{C}_{60}{ }^{[12 a, b]}$ or carbon nanotubes ${ }^{[12 \mathrm{c}, \mathrm{d}]}$ is achieved with rigid molecular tweezers where electron-donor binding sites are properly oriented by a rigid conjugated or aromatic spacer (Figure 5c). Similarly, metal ions of well-defined coordination geometry can control the relative orientation of two interaction sites. The latter strategy has been illustrated with square planar $\mathrm{Pt}^{\prime \prime}$ spacers maintaining two diverging electron donors thereby available to complex $\mathrm{C}_{60} .^{[12 b, e]}$

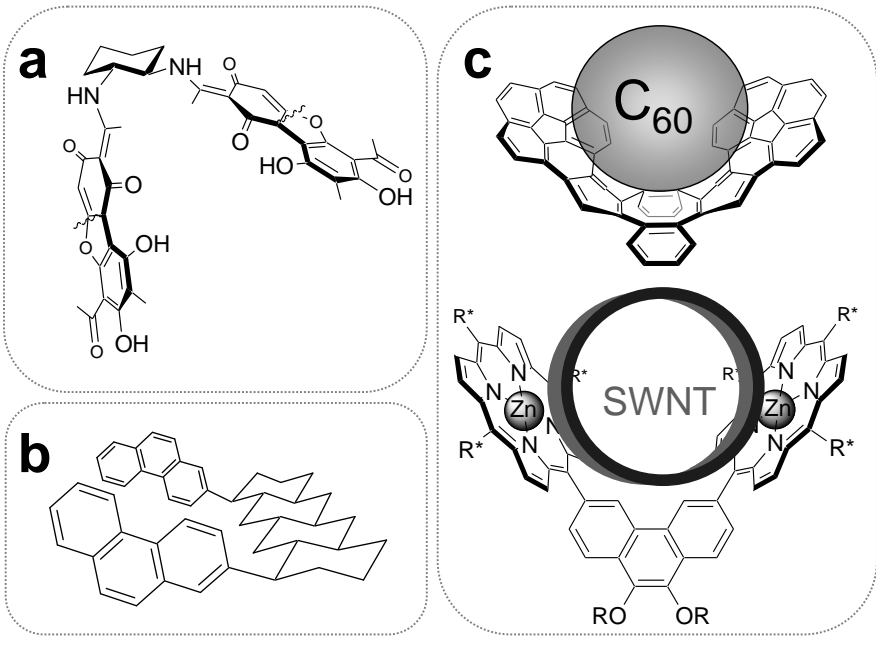

Figure 5: Rigid molecular tweezers based on cyclohexyl ${ }^{[11 a, b]}$ (a) and fused saturated $^{[11 \mathrm{c}-\mathrm{f}]}(\mathrm{b})$ or unsaturated ${ }^{[12 \mathrm{a}-\mathrm{c}]}$ (c) spacers. Substrates in (c) are fullerene $\left(\mathrm{C}_{60}\right)$ and single-walled carbon nanotubes (SWNT)

\subsection{Rigid spacers constructed around bicyclic units}


Another strategy to access rigid spacers is based on locking the conformation of semi-rigid spacers by 'strapping' two positions together via a bridge, thereby forming rigid, bicyclic connections (Figure 6a). ${ }^{[13]}$ The bicyclic structure may be centrally located only (as part of the spacer, e.g., 4a in Figure 6b) or repeated into the arm structure (e.g., $\mathbf{4 b}$ in Figure 6b). Because pinching in the latter is more pronounced, these receptors have been referred to as 'molecular tweezers' by their authors (e.g., $\mathbf{4 b}$ in Figure 6b). On the other hand, the more open cavity of the former relates them better to 'clips'. Such overall bicyclic design is attractive because of (i) easy synthetic access and functionalization (for instance by repetitive Diels-Alder/oxidation reactions), (ii) the variety of cavity sizes and shapes defined by the nature of the central 'upper' wall (e.g., benzene, naphthalene), (iii) the possible involvement of the latter in complex formation (e.g., naphthalene as electron-donor) and (iv) the control of the degree of 'wrapping' through the introduction of additional lateral bridges. Indeed, the geometry of such receptor greatly affects which type of substrate is best complexed: ${ }^{[13 c]}$ the 'clip' structure preferentially accommodates organic cations (such as NAD ${ }^{+}{ }^{[13 d]}$ thiamine ${ }^{[13 e]}$ and flavylium ${ }^{[13 f]}$ salts) by $\pi /$ cation and $\pi / \pi$ interactions, ${ }^{[13 d-f]}$ whereas the 'tweezer' one leads to a high selectivity for lysine and arginine, trapping the aliphatic chain inside the cavity. ${ }^{[13 g]}$ Due to their ability to selectively bind natural cofactors and amino-acid side chains, these systems have found applications and opened new perspectives in enzyme inhibition. ${ }^{[13 \mathrm{~d}, \mathrm{~h}, \mathrm{l}]}$ A similar design using larger $\mathrm{C} 2$ bridges $\left(-\mathrm{H}_{2} \mathrm{C}\right.$ $\mathrm{CH}_{2^{-}},{ }^{[13 \mathrm{j}]}-\mathrm{C}=\mathrm{C}-{ }_{-}{ }^{[13 \mathrm{k}]}$ Figure $6 \mathrm{a}$ ) and extended fused aromatic walls was applied to fullerene complexation with good affinities ( $\mathrm{K}=$ $3500 \mathrm{M}^{-1}$ in toluene/CHCl $\left.\mathrm{CH}_{3} 1: 1\right) .{ }^{[12 b, 13 j, k]}$ Other bridging structures such as ethers (-O-, Figure $6 \mathrm{a})^{[13 \mathrm{a}, 1]}$ and larger saturated cycles ${ }^{[13 \mathrm{~m}]}$ have also been explored and, being chiral, applied to the recognition of chiral guests. As a side note, although categorized as "rigid", bicyclic structures still allow some (restricted) conformational variations leading to small contractions upon substrate binding. ${ }^{[13 a]}$
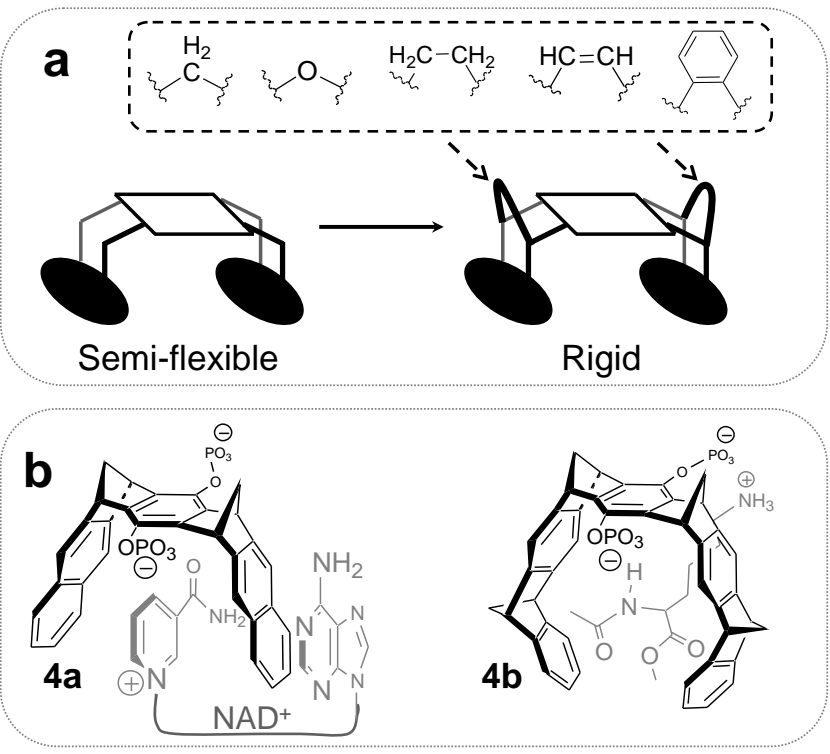

Figure 6. a) Transition from semi-flexible to rigid molecular tweezers through the introduction of bicyclic linkers; b) examples of molecular 'clips' (left) and 'tweezers' (right) and their selective complexation to organic cations such as $\mathrm{NAD}^{+}(\text {left })^{[13 \mathrm{c}]}$ and lysine derivatives (right). ${ }^{[13 \mathrm{f}]}$

\section{Spacers held in a pre-organized conformation through weak interactions}

\subsection{One state molecular tweezers: "on" binding state only}

As seen in 2.1, rigid spacers in molecular tweezers preorganize the interaction sites in a conformational state which is ready for substrate binding. In this respect, the entropic cost associated with the recruitment of the interaction sites around the substrate is paid in the course of the synthesis of the tweezer. However, such elaborate, fused covalent structures are sometimes fastidious to prepare. Alternatively, weak interactions may replace covalent links in order to fold the spacer into a conformation that is appropriate for substrate binding, and to simplify their synthesis. Amide-bond formation and aryl-aryl cross-coupling reactions are prime examples in the synthesis of pre-organized molecular tweezers.

As exemplified in nature, amide bonds are most important in controlling the conformation of molecules, and have extensively been used in an effort to fold artificial molecules into well-defined shapes. ${ }^{[14]}$ With the advent of peptide synthesis, preparation protocols are well-documented, and their chemical nature offers very good hydrogen-bond donor $(\mathrm{NH})$ and acceptor $(\mathrm{C}=\mathrm{O})$ sites. Figure 7 highlights how hydrogen-bonding information based on amide bonds has been used to generate pre-organized molecular tweezers of various sizes.
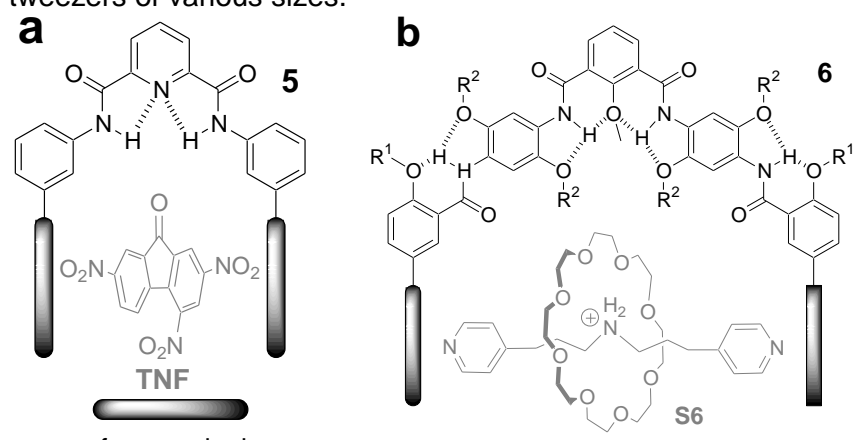

$=$ free porphyrin

or $\mathrm{Zn}$ (II) porphyrin complex

Figure 7: Amide bonds used in hydrogen-bonded pre-organized molecular tweezers (their substrates are indicated in grey).

The folded pyridyldiamide unit introduced by Hamilton ${ }^{[15 a]}$ has been applied to the construction of molecular tweezers (5 in Figure 7), among other folded architectures. In such reported molecular tweezers, the terminal arylamines are substituted with porphyrins or their complexes, allowing substrate complexation through $\pi-\pi$ and donor/acceptor interactions, as well as coordination bonds. ${ }^{[14 d, 15 b-f]}$ Although coordination bonds (e.g., to diamines such as $D A B C O$ ) are strong enough to enforce a cofacial geometry between two porphyrin complex interaction sites ${ }^{[15 e]}$ weaker interactions with the substrate such as $\pi-\pi$ and donor/acceptor interactions critically depend on the hydrogenbonded mediated pre-organization, and lead to reasonably tight substrate binding (e.g., $\mathrm{K}_{\text {assoc }}$ (5-free porphyrin / TNF) $=3.5( \pm$ $0.1) \times 10^{5} \mathrm{M}^{-1}$ in $\left.\mathrm{CDCl}_{3}\right) .{ }^{[15 f]}$ Molecular tweezers such as $\mathbf{5}$ having two planar and parallel electron donor sites (porphyrins) and a planar, rather electron-poor spacer tend to dimerize via the insertion of the spacer within the arms of another tweezer. The binding of electron-poorer substrates disrupts the dimer, a process which can be used to dissassemble supramolecular polymers made of "double tweezers". ${ }^{[15 f]}$ Increasing the cavity size as in 6 limits self-dimerization and allows to probe the recognition of more elaborate substrates, as shown in Figure $7 \mathrm{~b} .{ }^{[15 d]}$ Thanks to the pre-organization of the spacer through amide $\mathrm{N}-\mathrm{H} \cdots$...ether 
interactions, two porphyrin zinc complexes may be placed at an appropriate distance and orientation to synergistically coordinate two pyridine axial ligands from the substrate. Because the bridge between the two pyridines contains an ammonium site which readily interacts with crown-ethers in weakly polar solvents, the recruitment of the bis-pyridine strand within the arms of the tweezer leads to the formation of a rotaxane,$^{[16]}$ where the actual molecular tweezers play the role of stoppers. ${ }^{[15 d]}$ Smaller molecular tweezers based on the same $\mathrm{N}-\mathrm{H}$-..ether folding codon and interaction sites have also been prepared and complex electron-poor substrates such as $\mathrm{C}_{60}$ and $\mathrm{C}_{70}$ with association constants of the order of $10^{4}-10^{5} \mathrm{M}^{-1}$ in toluene. ${ }^{[15 \mathrm{~b}]}$

A similar design involving an amide-induced pre-organized spacer $\mathbf{S}$ based on a diaminophenazine rigid core combined with anionic aryl IS was applied to the selective biomimetic recognition of noradrenaline. ${ }^{[15 g]}$ Similarly, dihydrogen phosphate anions are selectively recognized by pre-organized molecular tweezers where two urea binding sites are appended to an anthraquinone core. ${ }^{[15 h]}$

Heteroaryl-heteroaryl connections offer a synthetically facile alternative to amide bonds, combined with conformational control. Inspired by the transoid conformational preference of 2,2'bipyridine,${ }^{[17 a]}$ the pyridine-pyrimidine-pyridine triad (7a-c, Figure 8) offers a similar cavity size as in $\mathbf{3} \mathbf{a A c r}_{2}$ (etheno bridges, Figures 4 and 8$).{ }^{[17 b]}$ On the one hand, $7 a$ decorated with electron-donor interaction sites (e.g., anthracenes) recognizes and complexes electron-acceptors. On the other hand, 7c, which is functionalized with electron-acceptors such as acridiniums, binds electron-rich substrates.

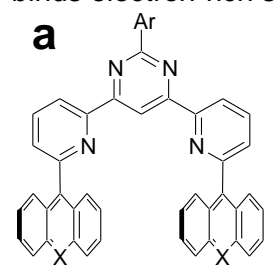

7a, $\mathrm{X}=\mathrm{CH}$

$7 b, X=N$

7c, $\mathrm{X}=\mathrm{N}\left(\mathrm{CH}_{3}\right)^{+}, \mathrm{TfO}^{-}$ b

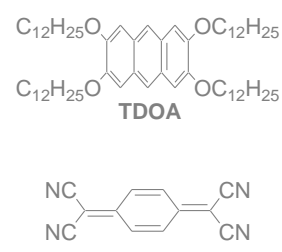

TCNQ

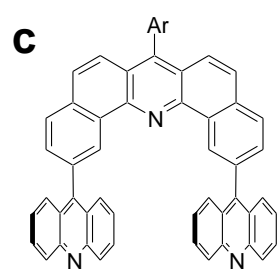

$3 \mathrm{aAcr}_{2}$ (bis etheno bridge)
Figure 8: a) Molecular tweezers based on the transoid conformational preference of 2,2'-bipyridine; b) electron-poor (TCNQ) and electron-rich (TDOA) substrates, $\left.{ }^{[17 b]} \mathrm{C}\right)$ covalently held analog for comparison. ${ }^{[9 b]}$

Table 1 gathers a few binding constants and allows assessing the effect of covalent vs non-covalent pre-organizations. Indeed, the bis-acridine weak donors in the rigid molecular tweezer $\mathbf{3 a A c r}$ bind TNF with a reported binding constant of $200 \mathrm{M}^{-1}$, ${ }^{[9 b]}$ whereas the non-covalently pre-organized analog $7 \mathrm{~b}$ complexes TNF with an association constant of $\sim 50 \mathrm{M}^{-1},{ }^{[17 \mathrm{~b}]}$ which is roughly four times smaller (see Figure 7 for the chemical structure of TNF). So there is a cost for not freezing the spacer into a covalent structure, very likely associated with the residual entropic freedom of rotation around $\mathrm{C}-\mathrm{C}$ bonds, but the association constants remain within the same order of magnitude.

Table 1. Reported binding constants for $7 \mathrm{a}-\mathbf{c}$ and $3 \mathbf{a A c r} 2$ (bis etheno bridge) expressed as $\log \left(\mathrm{K}_{\mathrm{assoc}}\right)$ at $25^{\circ} \mathrm{C} .^{[9 \mathrm{~b}, 17 \mathrm{~b}]}$

\begin{tabular}{|c|c|c|c|}
\hline Tweezers & $\mathrm{TNF}^{[\mathrm{a}]}$ & $\mathrm{TCNQ}^{[\mathrm{a}]}$ & $\operatorname{TDOA}^{[\mathrm{b}]}$ \\
\hline $7 a$ & $3.4 \pm 0.06$ & $3.79 \pm 0.05$ & - \\
\hline
\end{tabular}

$\begin{array}{lll}7 b & 1.7 \pm 0.2 & 2.0 \pm 0.1\end{array}$

$3 \mathrm{aAcr}_{2} \quad 2.3^{[9 \mathrm{~b}]}$

7c

$3.00 \pm 0.05$

[a] $\mathrm{CDCl}_{3} ;[\mathrm{b}] \mathrm{CDCl}_{3}+8 \% \mathrm{CD}_{3} \mathrm{OD}$

The above systems examplify how molecular tweezers can be easily prepared and tuned through the use of non-covalent interactions that fold the receptor into an active ("on") binding state. Because of the allowed bond rotations, these systems have the potential to be turned "on" and "off" by an external stimulus modifying the spacer's conformational preference, provided a second state is well-defined, as illustrated below.

\subsection{Two state molecular tweezers: "on" and "off" binding states}

\subsubsection{Metal lon triggered "on to off" and "off to on" switching}

As a matter of fact, molecular tweezers 7a-c display a second well-defined conformation derived from the chelation of metal ions by the bidentate pyridine-pyrimidine units. Such molecular tweezers have two well-defined conformational states, a neutral "substrate-binding on" state, and a metallated "substrate-binding off" state, where the large distance between IS and their relative orientation prevent efficient substrate binding (Figure 9a). ${ }^{[17 b, 18]}$ This overall 2-state process allows the controlled release of the bound substrate operated by a metal ion gradient. Similarly, pyridine-pyridine-pyridine triads $\mathbf{8}^{[17 b-d]}$ and isosters ${ }^{[17 e, f]}$ are capable of the reverse transformation, namely the metal-ion induced complexation of substrate, via an "off" to "on" conformational change (Figure 9b).

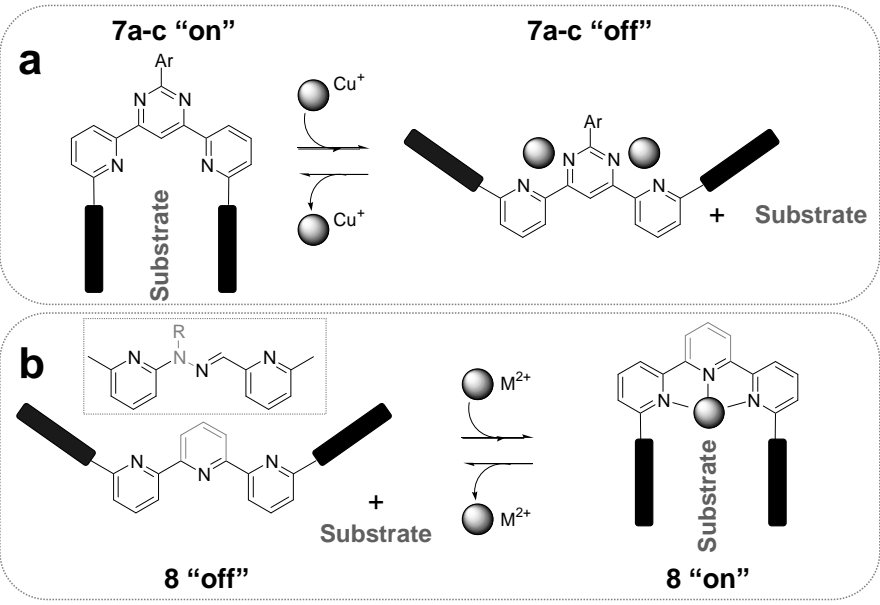

Figure 9: lon-triggered molecular tweezers. a) "on" to "off" substrate binding state conversion (grey substituents are anthracene, acridine or acridinium units) $;{ }^{[17 b]}$ b) "off" to "on" substrate binding state conversion (grey substituents are porphyrins, their $\mathrm{Zn}(\mathrm{II})$ or $\mathrm{Au}(\mathrm{II})$ complexes, ${ }^{[17 \mathrm{~d}]}$ anthracene derivatives ${ }^{[17 \mathrm{~b}]}$ or naphthalenediimide derivative ${ }^{[17 \mathrm{e}, \mathrm{f}]}$ units); the central pyridine is shaded of grey where the hydrazone isoster may be used (the hydrazone-based spacer is indicated in its "off" form in insert); ${ }^{[17 e, f]} \mathrm{M}^{2+}$ is $\mathrm{Zn}^{2+}, \mathrm{Cd}^{2+}$ or $\mathrm{Hg}^{2+}$.

3.2.2. Anion- and small-molecule controlled molecular tweezers

As an echo to cation-controlled molecular tweezers, anion control between two states is now emerging. Bis-indole 9 behaves similarly to 2,2 '-bipyridine: weak interactions ( $\mathrm{H}$-bonding 
mostly) favour a transoid conformation in the free state ("substrate-binding off" state), while anion binding recruits both $\mathrm{NH}$ functions to favour a cisoid conformation in the anion-bound state and induces a "substrate-binding on" state (Figure 10a). ${ }^{[19 a]}$ Such anion-controlled 2-state conformational switch has recently been explored in the development of molecular tweezers, where the interaction sites are, once again, porphyrin zinc complexes. ${ }^{[19 a]}$ One of the main challenges in this area is probably the relatively weaker binding constants for anion $\cdots \cdot \mathrm{H}-\mathrm{N}$ hydrogen bonding interactions compared with metal ion coordination, which limit the applicability to anion-triggered substrate binding. Yet, recent progress in anion based $\mathrm{H}$ bonding ${ }^{[19 b-d]}$ bodes well for the future of this field.

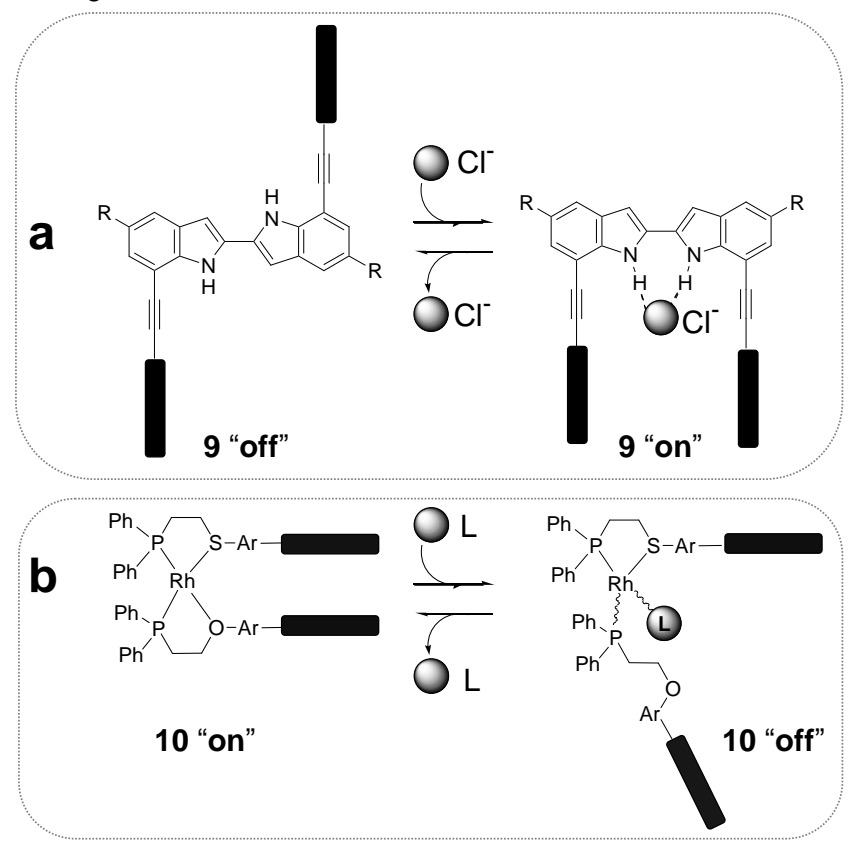

Figure 10: Anion-controlled (a) and small-molecule-controlled (b) molecular tweezers. Interactions sites (grey susbtituents) are porphyrin complexes; in b), L is either an anionic $(\mathrm{Cl})$ or neutral (CO) ligand; the "squiggly lines" between the rhodium and the ligands represents various coordination geometries.

Alternatively, anions may be used as triggers via their coordination to metal ions embedded in the spacer (10, Figure $10 \mathrm{~b})$, taking full advantage of the strength of coordination bonds (Figure 10b). ${ }^{[19 e, f]}$ Such ligand-controlled metal coordination geometry is not restricted to anionic ligands: small ligand molecules such as CO may also be used to tune the geometry of spacer 10, extending the technology to small-molecule controlled molecular tweezers.$^{[19 e, f]}$ Although substrate binding remains to be demonstrated in this context, there is no doubt that this technology bears tremendous potential.

\subsection{3. $\mathrm{pH}$ trigger}

More biologically relevant than metal ion gradient is a proton gradient. Recently, molecular tweezers $\mathbf{1 1}$ operated by $\mathrm{pH}$ gradients have been reported and proven to display differential interactions for bioactive substrates at different $\mathrm{pHs}$ (e.g., mitoxantrone, MTX, Figure 11). ${ }^{[20 a]}$ Such nanomachines hold promise for the selective drug delivery at the periphery of cancer cells where $\mathrm{pH}$ is significantly more acidic compared to healthy cells. $^{[20 b, c]}$ In this context, such dynamic molecular tweezers should enable instantaneous drug release, a valuable alternative to the more traditional, slower, $\mathrm{pH}$-promoted chemical hydrolysis of covalently held polymeric carriers. ${ }^{[20 d-g]}$

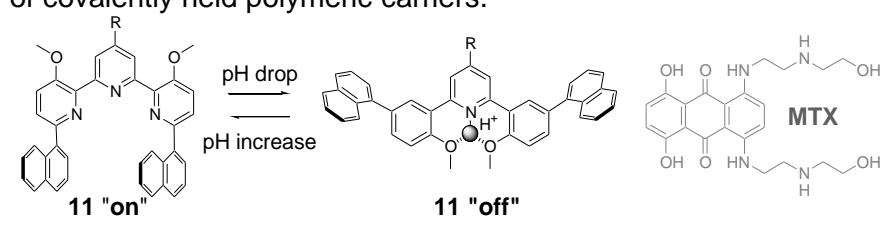

Figure 11: pH triggered "on" and "off" state of molecular tweezer 11 (left; $\mathrm{R}=\mathrm{H}$, $\mathrm{PEG}$ ) and its mitoxantrone (MTX) anti-cancer drug substrate (right, in grey). ${ }^{[20 \mathrm{a}]}$

\subsubsection{Electrochemical triggers}

Among the "cleanest" triggers operating molecular machines, redox processes are particularly attractive and have been investigated in the control of substrate binding by molecular tweezers. Electrochemically controlling substrate binding to molecular tweezers may be effected by (i) changing the properties of the substrate by redox transformations, ${ }^{[21 a]}$ and (ii) modifying the electronic properties of the molecular tweezers, and mostly the interaction sites, by oxidoreduction. Only the latter will be discussed below, with molecular tweezer 12 (Figure 12). ${ }^{[21 \mathrm{~b}]}$ Redox reactions on the interaction sites modify their charge and electronic properties, leading to electrostatically induced conformational switching. ${ }^{[21 b, c]}$ For instance, the two neutral, electron-rich TTF groups in $\mathbf{1 2}$ bind electron-poor substrates. Upon oxidation, both electron-rich interaction sites become positively charged and the resulting electrostatic repulsion favours the opening of the molecular tweezers, to a state where the substrate is expected to be less well bound. Although the substrate release process has not been probed yet due to weak binding in the "on" state, ${ }^{[21 b]}$ such electrochemical actuators appear particularly promising.

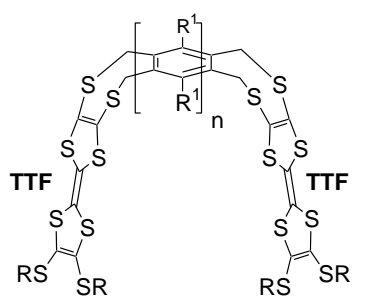

12 "on"

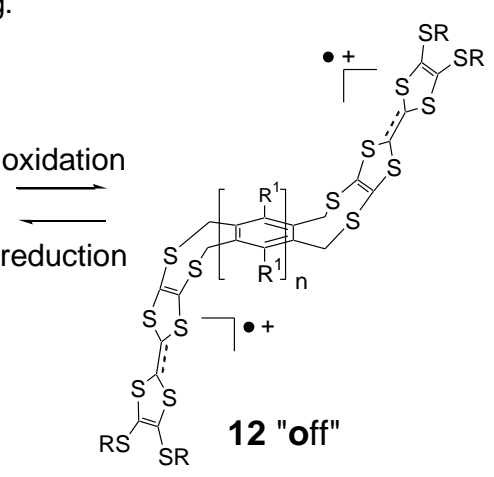

Figure 12: Electrochemically controlled molecular tweezers $12 .^{[21 \mathrm{~b}]}$

\subsubsection{Light trigger}

An alternative to electron-transfer as a "clean" and minimal trigger is provided by light/thermal relaxation, as illustrated by one of the very early molecular tweezers. ${ }^{[22]}$ UV radiation indeed converts the azo function in $\mathbf{1 3}$ from a trans "off" to a cis "on" conformation, where "ion sandwiching" is possible. ${ }^{[22]}$ This technology has been applied to trans-membrane ion transport, where UV-irradiation induces the complexation of potassium within the arms of the organic tweezers, is followed by transport of the complex through the membrane and by thermal relaxation to the trans "off" conformation in the dark compartment accompanied with potassium release (Figure 13). ${ }^{[2]}$ 
UV irradiation

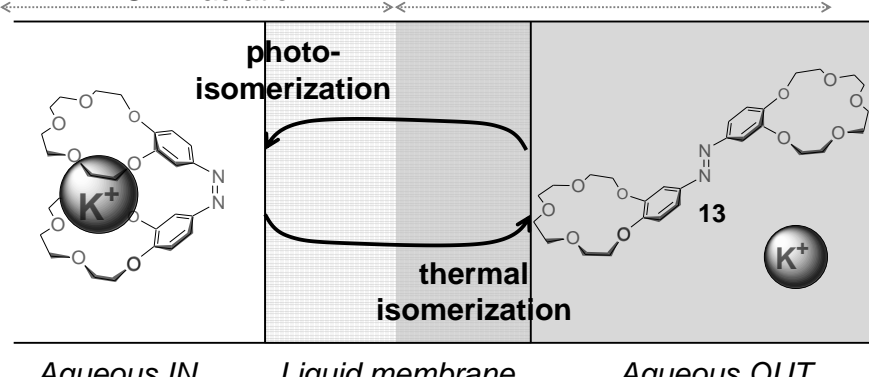

Figure 13: Light controlled molecular tweezers $\mathbf{1 3}$ applied to cation-binding, transmembrane transport and cation release. ${ }^{[22]}$

\section{Summary and Outlook}

In the last twenty years, molecular tweezers have developed into a rich field. Systems with rigid spacers combine selectivity and large association constants. Although they share those properties with macrocyclic receptors, they also offer lability in the diffusion in and out of the binding site. As far as applications are concerned, such lability is beneficial in the development of enzyme inhibitors and artificial catalysts. In this context, the dynamic "two state" molecular tweezers have a tremendous potential: trigger-controlled conformational switching may be used as an allosteric control element. Allosteric control is one of nature's critical tricks Chemists have long strived to mimic,$^{[1]}$ toward which dynamic molecular tweezers may contribute. The "on-state" where substrate is bound may be engineered to effect chemical transformation, and switched to the "off-state" in order to favour product release, an important aspect to limit productinduced catalyst inhibition. Other applications where motion and release are important, such as in molecular machines ${ }^{[23]}$ and in the transport ${ }^{[22]}$ and release of bio-active molecules ${ }^{[20 a]}$ may also successfully integrate molecular tweezer modules. Indeed, while much research effort has recently been focused on molecular motion within a single molecule or a mechanically held molecular assembly (e.g., topological molecules such as catenanes and rotaxanes), ${ }^{[16,23 b, e-g]}$ the controlled interaction between molecular machines either directly or via an intermediate effector, is a necessary step towards complex, integrated molecular machine networks, where dynamic molecular tweezers may play an important role. In a similar spirit involving communication within a complex network, further work mimicking biological signalling may include small molecule effectors as signalling elements. In this context, the manipulation of dynamic carriers for this molecular effector is essential. The carriers' ability to be transported from one compartment to another, and to be induced to uptake and release their cargo in a controlled manner is also critical, and molecular tweezers may, once again, provide important components.

\section{Acknowledgements}

The authors acknowledge the contribution of Professor JeanChristophe Leroux for inspiring this review and for very productive discussions, as well as the Université de Montréal, Queen's University, the Natural Science and Engineering Research Council of Canada, the Canadian Institutes of Health Research, the Ontario Ministry of Research and Innovation for financial support to the authors and their research programs.

Note: as this mini-review was being reviewed, a full review on a similar topic appeared in the literature. See: M. Hardouin-Lerough, P. Hudhomme and M. Sallé, Chem. Soc. Rev. 2011, 40, 30-43.

\section{Keywords: Supramolecular Chemistry · Molecular Recognition · Molecular Receptors · Pre-organization Molecular Switches}

[1] For selected reviews on allosteric control, see: a) J. Jr. Rebek, Acc. Chem. Res. 1984, 17, 258-264; b) J. M. Holtz, G. K. Ackers, Methods in Enzymology 1995, 259, 1-19; c) O. Jardetzky, Prog. Biophys. Molec. Biol. 1996, 65, 171-219; d) G. A. Soukup, R. R. Breaker, Curr. Opin. Struct. Biol. 2000, 10, 318-325.

[2] Z. Zhu, C. J. Cardin, Y. Gan, H.M. Colquhoun, Nature Chem. 2010, 2, 653-660.

[3] a) J.-M. Lehn, "Supramolecular Chemistry: Concepts and Perspectives", 1995, Wiley-VCH, Weinheim; b) P. Beer, P. Gale, D. Smith, "Supramolecular Chemistry", 1998, Oxford Chemistry Primers, Oxford University Press, Egland; c) J. W. Steed, J. L. Atwood, "Supramolecular Chemistry", 2000, John Wiley \& Sons.

[4] a) C.-W. Chen, H. W. J. Whitlock, J. Am. Chem. Soc. 1978, 100, 4921 4922; b) D. E. Koshland, Proc. Natl. Acad. Sci. USA. 1958, 44, 98-104.

[5] a) V. V. Borovkov, J. M. Lintuluoto, G. A. Hembury, M. Sugiura, R. Arakawa, Y. Inoue, J. Org. Chem. 2003, 68, 7176-7192; b) T. Kurtán, N Nesnas, F. E. Koehn, Y.-Q. Li, K. Nakanishi, N. Berova, J. Am. Chem. Soc. 2001, 123, 5974-5982; c) G. Proni, G. Pescitelli, X. Huang, K. Nakanishi, N. Berova, J. Am. Chem. Soc. 2003, 125, 12914-12927; d) H. Ishii, Y. Chen, R. A. Miller, S. Karady, K. Nakanishi, N. Berova, Chirality 2005, 17, 305-315; e) X. Li, M. Tanasova, C. Vasileiou, B. Borhan, J. Am. Chem. Soc. 2008, 130, 1885-1893; f) X.-X. Peng, H.-Y. Lu, T. Han, C.-F. Chen, Org. Lett. 2007, 9, 895-898; g) M.Orlowska, M. Mroczkiewicz, K. Guzow, R. Ostaszewski, A. M. Klonkowski, Tetrahedron 2010, 66, 2486-2491.

[6] a) J. Otsuki, H. Matsui, K. Imamura, I. Yoshikawa, K. Araki, M. Seno, Chem. Lett. 2001, 30, 1144-1145; b) L. Davidson, A. Blencowe, M.G. B. Drew, K. W. Freebairn, W. Hayes, J. Mater. Chem. 2003, 13, 758-766; c) H. Kurebayashi, T. Haino, S. Usui, Y. Fukazawa, Tetrahedron 2001, 57, 8667-8674; d) E. M. Pérez, L. Sánchez, G. Fernández, N. Martín, J. Am. Chem. Soc. 2006, 128, 7172-7173; e) M. Tanaka, K. Ohkubo, C. P. Gros R. Guilard, S. Fukuzumi, J. Am. Chem. Soc. 2006, 128, 14625-14633; f) T. Carofiglio, E. Lubian, I. Menegazzo, G. Saielli, A. Varotto, J. Org. Chem. 2009, 74, 9034-9043; g) L. Elisa, F. Baldini, A. Giannetti, C. Trono, T. Carofiglio, Chem. Commun. 2010, 46, 3678-3680; h) D. Jokic, C. Boudon, G. Pognon, M. Bonin, K. J. Schenk, M. Gross, J. Weiss, Chem. Eur. J. 2005, 11, 4199-4209; i) M., Palomino-Schätzlein, A. Virgili, S. Gil, C. Jaime, J. Org. Chem. 2006, 71, 8114-8120; j) J. N. H. Reek, H. Engelkamp, A. E. Rowan, J. A. A. W. Elemans, R. J. M. Nolte, Chem. Eur. J. 1998, 4, 716-722; k) P. Polavarapu, H. Melander, V. Langer, A. Gogoll, H. Grennberg, New J. Chem. 2008, 32, 643-651; I) Y.-M. Zhang, D.-D. Wang, Q. Lin, T.-B. Wei, Phosphorus, Sulfur, Silicon 2008, 183, 44-55; m) X. Su, K. Luo, Q. Xiang, J. Lan, R. Xie, Chirality 2009, 21, 539546; n) T. Nishiuchi, Y. Kuwatani, T. Nishinaga, M. Iyoda, Chem. Eur. J. 2009, 15, 6838-6847.

[7] a) K. Ghosh, A. R. Sarkar, A. Patra, Tetrahedron Lett. 2009, 50, 65576561 ; b) F. C. Krebs, M. Jorgensen, J. Org. Chem. 2001, 66, 6169-6173; c) L. Flamigni, A. M. Talarico, B. Ventura, R. Rein, N. Solladié, Chem. Eur. J. 2006, 12, 701-712; d) J. Jr. Rebek, Science 1987, 235 (4795), 1478-1484; e) J. Jr. Rebek, J. Inclusion Phenom. Mol. Recognit. Chem. 1989, 7, 7-17.

[8] a) E. Fischer, Chem. Ber. 1894, 27, 2985; b) H. Huang, D. G. Drueckhammer, Chem. Commun. 2006, 28, 2995-2997.

[9] a) S. C. Zimmerman, C. M. VanZyl J. Am. Chem. Soc. 1987, 109, 78947896; b) S. C. Zimmerman, C. M. VanZyl, G. S. Hamilton J. Am. Chem. Soc. 1989, 111, 1373-1381; c) Zimmerman, S. C. Top. Curr. Chem. 1993 165, 71-102; d) S. C. Zimmerman, Z. Zeng, W. Wu, D.E. Reichert, J. Am. Chem. Soc. 1991, 113, 183-196; e) S. C. Zimmerman, K. W. Saionz, J. Am. Chem. Soc. 1995, 117, 1175-1176. 
[10] a) R. D. Sommer, A. L. Rheingold, A. J. Goshe, B. Bosnich J. Am. Chem. Soc. 2001, 123, 3940-3952 ; b) A. J. Goshe, I. M. Steele, C. Ceccarelli, A L. Rheingold, B. Bosnich, Proc. Natl. Acad. Sci. USA 2002, 99, 48234829. c) J. D. Crowley, B. Bosnich, Eur. J. Inorg. Chem. 2005, 11, 2015 2025; d) D. Kim, S. Lee, G. Gao, H. Seok Kang, J. Ko, J. Organomet Chem. 2010, 695, 111-119; e) J. Brettar, J.-P. Gisselbrecht, M. Gross, N. Solladié, Chem. Commun. 2001, 8, 733-734; f) M. El Ojaimi, C. P. Gros, J.-M. Barbe, Eur. J. Org. Chem. 2008, 1181-1186.

[11] a) B. Legouin, M. Gayral, P. Uriac, S. Tomasi, P. van de Weghe, Tetrahedron Asymmetry 2010, 21, 1307-1310; b) B. Legouin, M. Gayral, P. Uriac, J.-F Cupif, N. Levoin, L. Toupet, P. van de Weghe, Eur. J. Inorg. Chem. 2010, 5503-5508; c) V. K. Potluri, U. Maitra J. Org. Chem. 2000 65, 7764-7769; d) J. Wang, X. Y. Yuan, J. Y. Wang, S. H. Chen, Chin. Chem. Lett. 2009, 20, 265-268; e) H. Nemoto, T. Kawano, N. Ueji, M. Bando, M. Kido, I. Suzuki, M. Shibuya, Org. Lett. 2000, 2, 1015-1017; f) H. Nemoto, T. Kawano, N. Ueji, N. Sakamoto, T. Araki, N. Miyoshi, I. Suzuki, M. Shibuya, Tetrahedron Lett. 2005, 46, 551-553.

[12] a) A. Sygula, F. R. Fronczek, R. Sygula, P. W. Rabideau, M. M Olmstead, J. Am. Chem. Soc. 2007 129, 3842-3843; b) E. M. Pérez, N. Martín, Pure Appl. Chem. 2010, 82, 523-533; c) F. Wang, K. Matsuda, M. A. F. M. Rahman, X. Peng, T. Kimura, N. Komatsu, J. Am. Chem. Soc 2010, 132, 10876-10881; d) R.Marquis, K. Kulikiewicz, S. Lebedkin, M. M. Kappes, C. Mioskowski, S. Meunier, A. Wagner, Chem. Eur. J. 2009 15, 11187-11196; e) J.-Y Balandier, M. Chas, P. I. Dron, S. Goeb, D. Canevet, A. Belyasmine, M. Allain, M. Sallé, J. Org. Chem. 2010, 75, 1589-1599.

[13] a) F.-G. Klärner, B. Kahlert, Acc. Chem Res. 2003, 36, 919-932; b) M Harmata, Acc. Chem. Res. 2004, 37, 862-873; c) M. Lobert, H. Bandmann, U. Burkert, U. P. Büchele, V. Podsadlowski, F.-G. Klärner Chem. Eur. J. 2006, 12, 1629-1641; d) F.-G. Klärner, T. Schrader, J. Polkowska, F. Bastkowski, P. Talbiersky, M. Campañá Kuchenbrandt, T. Schaller, H. de Groot, M. Kirsch, Pure Appl. Chem. 2010, 82, 991-999; e) T. Schrader, M. Fokkens, F.-G. Klärner, J. Polkowska, F. Bastkowski, J. Org. Chem. 2005, 70, 10227-10237; f) R. Gomes, A. J. Parola, F. Bastkowski, J. Polkowska, F.-G. Klärner, J. Am. Chem. Soc. 2009, 131 8922-8938; g) M. Fokkens, T. Schrader, F.-G. Klärner J. Am. Chem Soc. 2005, 127, 14415-14421; h) P. Talbiersky, F. Bastkowski, F.-G. Klärner , T. Schrader , J. Am. Chem. Soc. 2008, 130, 9824-9828; i) M. Kirsch, P. Talbiersky, J. Polkowska; F. Bastkowski, T. Schaller, H. de Groot, F.-G. Klärner, T. Schrader, Angew. Chem. Int. Ed. 2009, 48, 2886-2890; j) S. Bhattacharya, K. Tominaga, T. Kimura, H. Uno, N Komatsu, Chem. Phys. Lett. 2007, 433, 395-402; k) J. Cao, X.-Z. Zhu, C.-F. Chen, J. Org. Chem. 2010, 75, 7420-7423; I) S. P. Gaynor, M. J. Gunter, M. R. Johnston, R. N. Warrener, Org. Biomol. Chem. 2006, 4, 2253-2266; m) C.-J. Wallentin, T. Wixe, O. F. Wendt, K.-E. Bergquist, K. Wärnmark, Chem. Eur. J. 2010, 16, 3994-4002.

[14] a) S. H. Gellman, Acc. Chem. Res. 1998, 31, 173-180; b) D. J. Hill, M. J.Mio, R. B. Prince, T. S. Hughes, J. S. Moore, Chem. Rev. 2001, 101 , 3893-4011; c) W. S. Horne, S. H. Gellman, Acc. Chem. Res. 2008, 41, 1399-1408; d) X. Shao, Z.-T. Li, Chem. Commun. 2010, 46, 1601-1616.

[15] a) Y. Hamuro, S. J. Geib, A. D. Hamilton, Angew. Chem., Int. Ed. 1994 33, 446-448; b) Z.-Q. Wu, X.-B. Shao, C. Li, J.-L. Hou, K. Wang,X.-K. Jiang, Z.-T. Li, J. Am. Chem. Soc. 2005, 127, 17460-17468; c) T. Haino, T. Fuji, Y. Fukazawa, J. Org. Chem. 2006, 71, 2572-2580; d) J. Wu, F. Fang, W.-Y. Lu, J.-L. Hou, C. Li, Z.-Q. Wu, X.-K. Jiang, Z.-T. Li, Y.-H. Yu, J. Org. Chem. 2007, 72, 2897-2905; e) J. Etxebarria, A. Vidal-Ferran, P. Ballester, Chem. Commun. 2008, 5939-5941; f) T. Haino, T. Fuji, A Watanabe, U. Takayanagi, Proc. Nat. Acad. Sci. USA, 2009, 106, 14477 14481; g) O. Molt, D. Rübeling, T. Schrader J. Am. Chem. Soc. 2003 125, 12086-12087; h) S. O. Kang, S. Jeon, K. C. Nam, Supramol. Chem. 2002, 14, 405-410.

[16] a) J. A. Wisner, B. A. Blight, "Modern Supramolecular Chemistry", 2008, (Ed.: Diederich, Francois; Stang, Peter J.; Tykwinski, Rik R) 349-391; b) J. A. Faiz, V.Heitz, J.-P. Sauvage, Chem. Soc. Rev. 2009, 38, 422-442 c) J. D. Crowley, S. M. Goldup, A.-L. Lee, D. A. Leigh, R. T. McBurney, Chem. Soc. Rev. 2009, 38, 1530-1541; d) K. M. Mullen, P. D. Beer, Chem. Soc. Rev. 2009, 38, 1710-1713; e) D. B. Amabilino, L. PerezGarcia, Chem. Soc. Rev. 2009, 38, 1562-1571; f) J. F. Stoddart, Chem. Soc. Rev. 2009, 38, 1802-1820; g) P. Gavina, S. Tatay, Curr. Org. Synth. 2010, 7, 24-43; h) K. D. Haenni, D. A. Leigh, Chem. Soc. Rev. 2010, 39 , 1240-1251; i) S. Durot, F. Reviriego, J.-P. Sauvage, Dalton. Trans. 2010 , 39, 10557-10570.

[17] a) S. T. Howard J. Am. Chem. Soc. 1996, 118, 10269-10274; b) A. Petitjean, R. G. Khoury, N. Kyritsakas, J.-M. Lehn, J. Am. Chem. Soc. 2004, 126, 6637-6647; c) M. Barboiu, L. Prodi, M. Montalti, N. Zaccheroni, N. Kyritsakas, J.-M. Lehn, Chem. Eur. J. 2004, 10, $2953-$ 2959; d) M. Linke-Schaetzel, C. E. Anson, A. K. Powell, G. Buth, E. Palomares, J. D. Durrant, T. S. Balaban, J.-M. Lehn, Chem. Eur. J. 2006 12, 1931-1940; e) S. Ulrich, J.-M. Lehn, Chem. Eur. J. 2009, 15, 56405645; f) S. Ulrich, A. Petitjean, J.-M. Lehn, Eur. J. Inorg. Chem. 2010, 13 1913-1928.

[18] As a matter of fact, the pyridine-pyrimidine-pyridine conformational switch really is a 3-state system. For 2, 3 and 4-state systems based on this motif, see A. Petitjean, N. Kyritsakas, J.-M. Lehn, Chem. Eur. J. 2005, 11, 6818-6828.

[19] a) C.-H. Lee, H. Yoon, W.-D. Jang, Chem. Eur. J. 2009, 15, 9972-9976 and references therein; b) G. Philip, Chem. Soc. Rev. 2010, 39, 37463771 ; c) V. Amendola, L. Fabbrizzi, L. Mosca, Chem. Soc. Rev. 2010, 39, 3889-3915; d) Y. Hua, A. H. Flood, Chem. Soc. Rev. 2010, 39, 12621271 ; e) C. G. Oliveri, P. A. Ulmann, M. J. Wiester, C. A. Mirkin, Acc. Chem. Res. 2008, 41, 1618-1629; f) C. G. Oliveri, S. T. Nguyen, C. A. Mirkin, Inorg. Chem. 2008, 47, 2755-2763.

[20] a) J. Leblond, H. Gao, A. Petitjean, J.-C. Leroux, J. Am. Chem. Soc. 2010, 132, 8545-8555; b) E. S. Lee, Z. Gao, Y. H. Bae, J. Controlled Release 2008, 132, 164-170; c) S. Harguindey, J. L. Arranz, M. L. Wahl, G. Orive, S. J. Reshkin, Anticancer Res. 2009, 29, 2127-2136; d) K. Ulbrich, V. Šubr, Adv. Drug Delivery Rev. 2004, 56, 1023-1050; e) E. R. Gillies, J. M. Frechet, Bionconj. Chem. 2005, 16, 361-368; f) R. Jain, S. M. Standley, J. M. Frechet, Macromolecules 2007, 40, 452-457; g) R. Tong, J. Cheng, Polym. Rev. 2007, 47, 345-381.

[21] a) V. Balzani, H. Bandmann, P. Ceroni, C. Giansante, U. Hahn, F.-G. Klärner, U. Müller, W. M. Müller, C. Verhaelen, V. Vicinelli, F. Vögtle, J. Am. Chem. Soc. 2006, 128, 637-648; b) M. Skibiński, R. Gómez, E. Lork, V. A. Azov, Tetrahedron 2009, 65, 10348-10354; c) G. Pognon, C. Boudon, K. J. Schenk, M. Bonin, B. Bach, J. Weiss, J. Am. Chem. Soc. 2006, 128, 3488-3489.

[22] S. Shinkai, T. Nakaji, T. Ogawa, K. Shigematsu, O. Manabe, J. Am. Chem. Soc. 1981, 103, 111-115.

[23] For selected reviews, see: a) V. Balzani, A. Credi, F. M. Raymo, J. F. Stoddart, Angew. Chem., Int. Ed. 2000, 39, 3348-3391; b) J.-P. Collin, J.P. Sauvage, Chem. Lett. 2005, 34, 742-747; c) W. R. Browne, B. L. Feringa, Nat. Nanotechnol. 2006, 1, 25-35; d) E. R. Kay, D. A. Leigh, F. Zerbetto, Angew. Chem., Int. Ed. 2007, 46, 72-191; e) S. Loeb, Chem. Soc. Rev. 2007, 36, 226-235; f) B. Champin, P. Mobian, J.-P. Sauvage, Chem. Soc. Rev. 2007, 36, 358-366; g) J.-P. Sauvage, J.-P. Collin, S. Durot, J. Frey, V. Heitz, A. Sour, C. Tock, C. R. Chim. 2010, 13, 315328.

Received: ((will be filled in by the editorial staff))

Published online: ((will be filled in by the editorial staff)) 


\section{Entry for the Table of Contents}

\section{MINIREVIEWS}

Aimed at controlled substrate binding,

molecular tweezers have been

Jeanne Leblond, Anne Petitjean*

engineered to offer a range of flexibility degrees and a variety of interaction sites for substrate binding. Applications ranging from molecular recognition, molecular electronics, enzyme inhibition, the assembly of complex topological systems, and to drug carriers are emerging, and show
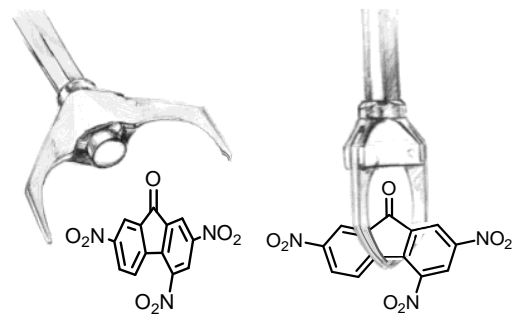

Page No. - Page No.

Molecular Tweezers: Concepts and Applications 